\title{
The Preparation Methods of Gallium Nitride Powder
}

\author{
Wen-Zhi YANG ${ }^{1, a, *}$, Wei HUANG ${ }^{1,2, b}$, Ya-Feng LI ${ }^{3, c}$, Wei-Ming HUANG ${ }^{1, d}$, \\ Fu-Jun SHANG ${ }^{1, e}$, Zi-Ming CHEN $^{1, f}$ \\ ${ }^{1}$ Ningbo Branch of China Academy of Ordnance Science, Ningbo, 315103, China \\ ${ }^{2}$ College of Mechanical Engineering and Mechanics, Ningbo University, Ningbo, 315103, China \\ ${ }^{3}$ Zhejiang Business Technology Institute, Ningbo, 315103, China \\ aemail:yangwenzhith@163.com, bemail:hw315@126.com, 'email:lyf1128@126.com, \\ demail:diinm11@163.com, ${ }^{,} e m a i l: s f j n b @ 126 . c o m,{ }^{\dagger}$ email:czmwm@163.com
}

${ }^{*}$ Corresponding author

Keywords: Gallium nitride; Preparation methods; Nano powder

\begin{abstract}
Gallium nitride $(\mathrm{GaN})$ has attracted much attention for a long time as a promising material for semiconductor device application in the transistors, visible light-emitting sources and high powder diodes. Many investigations are paid to the synthesis method, the process of crystal growth, structure and optical properties of GaN powder and its film. In this article, the preparation methods of GaN powder using the different kinds of raw materials have been reviewed.
\end{abstract}

\section{Introduction}

Due to outstanding physical properties such as high thermal conductivity, wide and direct band gap, low compressibility, the Gallium nitride $(\mathrm{GaN})$ has attracted considerable attentions in recent years for its application in optical devices [1]. Because its direct band gap energy is to be $3.4 \mathrm{eV}$, the research interesting is focus on the optical properties of GaN. Most studies of GaN have been made in synthesizing nanopowder [2], membranes [3], nanorods [4], and bulk single crystals [5].

In the present work, the synthesis methods of $\mathrm{GaN}$ powder through the different kinds of raw materials ( $\mathrm{Ga}, \mathrm{Ga}_{2} \mathrm{O}_{3}, \mathrm{GaI}_{3}$, and other $\mathrm{Ga}$ compounds) have been reviewed, and the characteristics of preparation methods have also been discussed.

\section{Preparation Methods of Gallium Nitride Powder}

\section{Ga Metal as Raw Materials}

Due to excellent characteristics like high efficient and contamination-free, plasma method was an important method to synthesize GaN nanopowder using Ga metal and $\mathrm{NH}_{3} / \mathrm{N}_{2}$ as raw materials. Li et al $[6,7]$ had fabricated ultrafine hexagonal GaN powder with the size about $20-200 \mathrm{~nm}$ using the dc arc plasma method. Their investigation demonstrated that the conversion of $\mathrm{Ga}$ metal to $\mathrm{GaN}$ nanopowder was determined by the mixture ration of $\mathrm{NH}_{3}$ and $\mathrm{N}_{2}$ in the mixture gas. Furthermore, Raman spectroscopy of nanocrystalline GaN was observed. The characteristics modes exhibited that the size and defected-related effects on the lattice vibrational properties of the GaN nanopowder [8]. In addition, $\mathrm{GaN}$ particles were synthesized by the reaction of molten $\mathrm{Ga}$ and ammonia using $\mathrm{Bi}$ as a catalyst. The Bi catalyst was effective at increasing the growth rate of GaN powder, and it was easily removed by evaporation to obtain the high purity powders [9].

Xiang et al reported that the single-crystalline $\mathrm{GaN}$ nanobelts were synthesized by gallium vapor and ammonia using $\mathrm{Ni}$ as a catalyst [10]. GaN nanobelts were grown on the $\mathrm{Ni}$-deposited silicon substrate at $950{ }^{\circ} \mathrm{C}$ for $60 \mathrm{~min}$ with the flow of $\mathrm{NH}_{3}(50 \mathrm{ml} / \mathrm{min})$. High purity $\mathrm{GaN}$ nanos tructure with hexagonal wurtzite structure is belt-like, which the thickness and width is about $30 \mathrm{~nm}$ and 200 $\mathrm{nm}$, respectively. The lengths of nanobelts are up to several tens of $\mu \mathrm{m}$, which appear twist and waving shapes. 
The system investigations by $\mathrm{Xu}$ and coworkers [11] indicated that GaN particles were obtained by three different ways using the same Ga as a precursor. First of all, Ga metal (99.999\% purity) and $\mathrm{NH}_{4} \mathrm{I}$ (99.9\% purity) were used as raw material to synthesize $\mathrm{GaN}$ particle by ammonothermal method. The nanoparticle of cubic $\mathrm{GaN}$ with grain size $32 \mathrm{~nm}$ was obtained. And then, $\mathrm{NH}_{4} \mathrm{I}$ was replaced by $\mathrm{NH}_{4} \mathrm{Cl}$ (99.9\% purity), and the molar ration of $\mathrm{Ga}$ to $\mathrm{NH}_{4} \mathrm{Cl}$ is 82:18. The high pure hexagonal GaN particle with $20 \mathrm{~nm}$ was also obtained by ammonothermal method. At last, a gas reaction route was used to obtain pure hexagonal $\mathrm{GaN}$ coarse-grain powder. $\mathrm{NH}_{3}$ gas $(200 \mathrm{ml} / \mathrm{min}$ for 4-6 h) was adopted as a nitrogen source. The study ind ic ated that the crystal structure and grain size of GaN particle are significantly influenced by raw material and synthesis method.

Single crystal of GaN powder with $1.5 \times 1 \times 0.1 \mathrm{~mm}$ was also prepared from Ga vapours and ammonia $(99.99 \%)$ at the temperature of $850-1150{ }^{\circ} \mathrm{C}$ [12]. The temperature in the zones of the reactor and the gas flow rate are the key factors on the shape and growth rate of GaN crystals. Both the X-ray diffraction and Raman spectroscopy demonstrated that the crystallographic structure of the crystals and powders was well pronounced. There was another way to obtain the monocrystalline GaN. Vodakov et al showed that the monocrystalline GaN epitaxial layers were deposited by the sublimation "sandwich method"(SSM) with growth rate as high as $1 \mathrm{~mm} / \mathrm{h}$ at temperature from $1100{ }^{\circ} \mathrm{C}$ to $1250{ }^{\circ} \mathrm{C}$ in the flow of ammonia [13]. High-purity and high efficient are the advantages using $\mathrm{Ga}$ as raw materials. However, there are still are disadvantages. For examples, the particle size of $\mathrm{GaN}$ is difficult to control by ammonothermal method.

\section{$\mathrm{Ga}_{2} \mathrm{O}_{3}$ as Raw Materials}

Using $\mathrm{Ga}_{2} \mathrm{O}_{3}$ as a raw material to synthesize was fully investigated by many methods. Zhao et al [14] reported that $\mathrm{GaN}$ nanobelts with wurtzite structure were grown on $\mathrm{Ni}$-coated $\mathrm{LaAlO}_{3}$ substrate by milling $\mathrm{Ga}_{2} \mathrm{O}_{3}$ under $\mathrm{NH}_{3}$ atmosphere. The growth direction of $\mathrm{GaN}$ nanobelts is parallel to [210]. The formation process could be a two-step chemical reaction as the following: (1) $\mathrm{Ga}_{2} \mathrm{O}_{3}(\mathrm{~s})+2 \mathrm{H}_{2}(\mathrm{~g}) \rightarrow \mathrm{Ga}_{2} \mathrm{O}(\mathrm{s})+2 \mathrm{H}_{2} \mathrm{O}(\mathrm{g})$; (2) $\mathrm{Ga}_{2} \mathrm{O}_{3}(\mathrm{~g})+2 \mathrm{NH}_{3}(\mathrm{~g}) \rightarrow 2 \mathrm{GaN}(\mathrm{s})+\mathrm{H}_{2} \mathrm{O}(\mathrm{g})+2 \mathrm{H}_{2}(\mathrm{~g}) . \quad \mathrm{H}_{2}$ is generated from $\mathrm{NH}_{3}$ at the high temperature in the reactions. Photoluminescence (PL) spectrum demonstrated that $\mathrm{GaN}$ nanobelts showed a broad strong emission peak at $2.65 \mathrm{eV}$ in the blue range. In addition, $\mathrm{GaN}$ particles were synthesized by milling $\mathrm{Ga}_{2} \mathrm{O}_{3}$ and $\mathrm{Li}_{3} \mathrm{~N}$ at a molar ratio of $1: 2$ under ammonia atmosphere with the speed of 300rpm for $2 \mathrm{~h}$ [15]. However, this method to obtain GaN particles had a fatal drawback. There were many by-products such as $\mathrm{Li}_{2} \mathrm{O}, \mathrm{LiOHH}_{2} \mathrm{O}, \mathrm{Li}_{5} \mathrm{GaO}_{4}$ and so on. The removal process was a time-consuming, complicated and expensive process.

$\mathrm{GaN}$ nanopowder with the particles size from 10 to $30 \mathrm{~nm}$ had been prepared by combustion method [16]. Firstly, $\mathrm{Ga}_{2} \mathrm{O}_{3}$ and $\mathrm{HNO}_{3}$ were put into vessel to obtain the solution. The solution was dried by microwave reactor, which could stimulate and accelerate the conversion of $\mathrm{Ga}_{2} \mathrm{O}_{3}$ into $\mathrm{Ga}\left(\mathrm{NO}_{3}\right)_{3}$. And then, $\mathrm{Ga}\left(\mathrm{NO}_{3}\right)_{3}$ placed in an alumina crucible were calcinated at $600{ }^{\circ} \mathrm{C}$ for $6 \mathrm{~h}$ in the air to obtain $\mathrm{Ga}_{2} \mathrm{O}_{3}$ again. Finally, $\mathrm{Ga}_{2} \mathrm{O}_{3}$ powder was heated at $1050{ }^{\circ} \mathrm{C}$ under $\mathrm{NH}_{3}$ atmosphere for $5 \mathrm{~h}$ to get high pure $\mathrm{GaN}$ with a wurtzite type structure. The optical properties of $\mathrm{GaN}$ nanopowder were related closely to the grain size of particles. The emission peak of GaN band gap disappeared as grain size was less than $10 \mathrm{~nm}$. This was attributed to the surface-to-volume ratio.

$\mathrm{Di}$ Lello et al synthesized the GaN powder by two routes [17]. One is gas-solid reaction from $\mathrm{Ga}_{2} \mathrm{O}_{3} / \mathrm{NH}_{3}$ system, the other is from $\mathrm{Ga}_{2} \mathrm{O}_{3} / 3 \mathrm{C} / \mathrm{NH}_{3}$ reaction system. The $\mathrm{X}$-ray diffraction results demonstrated that both $\mathrm{GaN}$ and unreacted $\mathrm{Ga}_{2} \mathrm{O}_{3}$ powder existed in $\mathrm{Ga}_{2} \mathrm{O}_{3} / \mathrm{NH}_{3}$ system. The high quality $\mathrm{GaN}$ powder can be obtained by optimizing the quality of carbon source, the $\mathrm{Ga}_{2} \mathrm{O}_{3} / \mathrm{C}$ ratio and reactions parameters using the $\mathrm{Ga}_{2} \mathrm{O}_{3} / 3 \mathrm{C} / \mathrm{NH}_{3}$ reaction system.

Wang et al [18] reported that single-crystal $\mathrm{GaN}$ nanowires were fabricated on $\mathrm{Si}$ substrates through evaporating $\mathrm{Ga}_{2} \mathrm{O}_{3}$ powder at $1100{ }^{\circ} \mathrm{C}$ in ammonia gas flow by chemical vapor deposition (CVD) method. Their experiments demonstrated that appropriate temperature, ammonia, $\mathrm{NiCl}_{2}$ layer, and $\mathrm{Ga}_{2} \mathrm{O}_{3}$ have a crucial influence on the growth process of $\mathrm{GaN}$ nanowires. Furthermore, they indicated that the liquid droplets exist at the tips of the nanowires, which demonstrated that the growth mechanism of GaN nanowires is VLS mechanism. There is a common way to obtain GaN powder using $\mathrm{Ga}_{2} \mathrm{O}_{3}$ as raw materials. But it has many weaknesses such as lower purity, complex 
process. For example, the distribution of particle size of GaN nanopowder is uncontrollable and low purity by combustion method. The CVD method is a time consuming process.

\section{$\mathrm{GaI}_{3}$ as Raw Materials}

Spherical GaN nano particles with hexagonal structure were prepared from sodium azide using iodine as a heat sink and diluents [19]. X-ray photoelectron spectra (XPS) of the as-prepared GaN powder with an average size of $30 \mathrm{~nm}$ demonstrated that the surface element molar ration of Ga to $\mathrm{N}$ is 1:0.94. Photoluminescence (PL) spectrum at room temperature exhibited that GaN nanoparticles had one broad weak emission peak at $365 \mathrm{~nm}$.

$\mathrm{Xu}$ and coworkers [20,21] had completed many interesting researches about synthesizing single-crytalline $\mathrm{GaN}$ at low temperature using $\mathrm{GaI}_{3}$ as a precursor. They synthesized $50 \mathrm{~nm}$ GaN powder with rocksalt structure by the reaction of $\mathrm{GaI}_{3}$ and $\mathrm{NaNH}_{2}$ at $210{ }^{\circ} \mathrm{C}$ under $3 \mathrm{MPa}$ pressure, employing $\mathrm{I}_{2}$ acted as the transporting agent. The entire process could be described by the following equation: (1) $3 \mathrm{NaNH}_{2} \rightarrow \mathrm{Na}_{3} \mathrm{~N}+\mathrm{NH}_{3}$; (2) $\mathrm{GaI}_{3}+\mathrm{Na}_{3} \mathrm{~N} \rightarrow \mathrm{GaN}+3 \mathrm{NaI}$. The X-ray photoelectron spectra (XPS) analysis demonstrated that the average composition of $\mathrm{Ga}: \mathrm{N}$ is 1.14: 1. Furthermore, they synthesized $\mathrm{GaN}$ microspindles using a solid state reaction of $\mathrm{GaI}_{3}, \mathrm{NH}_{4} \mathrm{Cl}$ and $\mathrm{NaNH}_{2}$ at $500{ }^{\circ} \mathrm{C}$ for $6 \mathrm{~h}$ [20]. The GaN microspindles were composed of many single-crystalline platelets, which were observed by high-resolution transmission electron microscopy (HRTEM). The shape of GaN microspindles had significantly influenced on optical properties. These works suggested that it may be possible to synthesize high pure $\mathrm{GaN}$ nanopowder at low temperature. Compared with $\mathrm{Ga}$ and $\mathrm{Ga}_{2} \mathrm{O}_{3}, \mathrm{GaI}_{3}$ is not extensively used in industry production as chemistry material. The method using $\mathrm{GaI}_{3}$ as raw materials are some problem such as time consuming, low purity and toxic by-products.

\section{Other Ga Compounds as Raw Materials}

Xie et al [22] firstly reported that the $\mathrm{GaN}$ nanoparticles were prepared by the thermal reaction of $\mathrm{Li}_{3} \mathrm{~N}$ and $\mathrm{GaCl}_{3}$. The reaction was under the benzene solvent at $280{ }^{\circ} \mathrm{C}$, and the yield of hexagonal $\mathrm{GaN}$ with particle size of $30 \mathrm{~nm}$ reached $80 \%$. In addition, wurtzite GaN nanorods were synthesized by solid-state reaction through the reaction of $\mathrm{NaNH}_{2}$ and $\mathrm{GaOOH}$ nanorods at $600{ }^{\circ} \mathrm{C}$. This method was regards as an atom-economical and eco-friendly chemical synthetic route. The GaN nanorods with the length of 400-600 $\mathrm{nm}$ and the diameters 80-150 $\mathrm{nm}$ showed strong blue emission by photoluminescence tests [23]. However, $\mathrm{GaCl}_{3}$ is hypertoxic and not suitable for industrial production.

\section{Conclusion}

$\mathrm{GaN}$ is one of the most promising materials for application in optical and high powder electronic devices. GaN powders are synthesized by many methods such as dc arc plasma, milling, and combustion method and so on. However, there are still some drawbacks. Most methods are time consuming process, and not suitable for industrial production. Some preparation processes are complicated and miscellaneous. Due to the lack of a simple, efficient, and inexpensive synthesis approach, the industrial production of high purity GaN powders have been hampered in a certain extent. It is important to explore a simple process having the ability of producing GaN powders with high purity and efficient.

\section{Acknowledge ment}

This research was financially supported by the Nature Science Foundation of Zhejiang Province (Project No. LQ15E070002), the Nature Science Foundation of Ningbo (Project No. 2015A610004). 


\section{References}

[1] H.Q. Wu, P. Konkapaka, Y. Makarov, M.G. Spencer, Bulk GaN growth by gallium vapor transport technique, Phys. Stat. Sol. (c) 2 (2005) 2032-2035.

[2] H.D. Xiao, H.L. Ma, C.S. Xue, J. Ma, F.J. Zong, X.J. Zhang, F. Ji, W.R. Hu, Synthesis and structural properties of GaN powders, Mater. Chem. Phys. 88 (2004) 180-184.

[3] T. Maruyama, H. Miyake. Gallium nitride thin films deposited by radio-frequency magnetron sputtering, J. Vacuum Sci. Technol. A 2006 (24) 1096-1099.

[4]Y.J. Ai, C.S. Xue, C.W. Sun, L.L.Sun, H.Z. Zhuang, F.X. Wang, H. Li, J.H. Chen, Synthesis of $\mathrm{GaN}$ nanowires through $\mathrm{Ga}_{2} \mathrm{O}_{3}$ film' reaction with ammonia, Mater. Lett. 61 (2007) 2833-2836.

[5]S.Y. Zhang, H.Z. Zhuang, C.S. Xue, B.L. Li, D.X. Wang, J.B. Shen, Synthesis and optical properties of single-crystalline GaN nanorods, Vacuum, 82 (2008) 539-542.

[6] H.D. Li, H.B. Yang, S. Yu, G.T. Zou, Y.D. Li, S.Y. Liu, S.R. Yang, Synthesis of ultrafine gallium nitride powder by the direct current arc plasma method, Appl. Phys. Lett. 69 (1996) 1285-1287.

[7] H.D. Li, H.B. Yang, G.T. Zou, S. Yu, J.S. Lu, S.C. Qu, Y. Wu, Formation and photoluminescence spectrum of w-GaN powder, J. Cryst. Growth 171 (1997) 307-310.

[8] H.D. Li, S.L. Zhang, H.B. Yang, G.T. Zou, Y.Y. Yang, K.T. Yue, X.H. Wu, Y. Yan, Raman spectroscopy of nanocrystalline GaN synthesized by arc plasma, J. Appl. Phys. 91 (2002) 4562-4567.

[9] H.Q. Wu, J. Hunting, K. Uheda, L. Lepak, P. Konkapaka, F.J. DiSalvo, M.G. Spencer, Rapid synthesis of gallium nitride powder, J. Cryst. Growth 279 (2005) 303-310.

[10] X. Xiang, C.B. Cao, H.S. Zhu, Catalytic synthesis of single-crystalline gallium nitride nanobelts, Solid State Comm. 126 (2003) 315-318.

[11] Y.P. Xu, W.Y. Yang, D.F. Zhang, X.L. Chen, Dielectric properties of GaN nanoparticles, J. Mater. Sci. 36 (2001) 4401-4403.

[12] G. Kamler, J. Zachara, S. Podsiadlo, L. Adamowicz, W. Gebicki, Bulk GaN single-crystals growth, J. Cryst. Growth 212 (2000) 39-48.

[13] Y.A. Vodakov, E.N. Mokhov, A.D. Roenkov, M.E. Boiko, P.G. Baranov, High rate GaN epitaxial growth by sublimation sandwich method, J. Cryst. Growth 183 (1998) 10-14.

[14] M. Zhao, X.L. Chen, J.K. Jian, X.N. Zhang, H.Z. Zhao, Y.P. Xu, Growth and optical characterization of high-quality GaN nanobelts, J. Cryst. Growth 283 (2005) 418-424.

[15] J. Kano, E. Kobayashi, W. Tongamp, F. Saito, Preparation of GaN powder by mechanochemical reaction between $\mathrm{Ga}_{2} \mathrm{O}_{3}$ and $\mathrm{Li}_{3} \mathrm{~N}$, J. Alloy. Compd. 464 (2008) 337-339.

[16] R. Kudrawiec, M. Nyk, M. Syperek, A. Podhorodecki, J. Misiewicz, W. Strek, Photoluminescence from GaN nanopowder: The size effect associated with the surface-to-volume ratio, Appl. Phys. Lett. 88 (2006) 181916.

[17] B.C. Di Lello, F.J. Moura, I.G. Solorzano, Synthesis and characterization of GaN using gas-solid reactions, Mater. Sci. Eng. B93 (2002) 219-223.

[18] Y. Wang, C.S. Xue, H.Z. Zhuang, Z.P. Wang, D.D. Zhang, Y.L. Huang, W.J. Liu, Synthesis and characterization of GaN nanowires, Appl. Surf. Sci. 255 (2009) 7719-7722.

[19] J. Q. Hu, B. Deng, W.X. Zhang, K.B. Tang, Y.T. Qian, Gallium nitride synthesis from sodium azide using iodine as a heat sink and diluents, Chem. Phys. Lett. 351 (2002) 229-234. 
[20] F. Xu, Y. Xie, X. Zhang, S.Y. Zhang, L. Shi, A benzene-thermal metathesis route to pure metastable rocksalt GaN, New J. Chem. 27 (2003) 565 - 567.

[21] F. Xu, Y. Xie, X. Zhang, S.Y. Zhang, X.M. Liu, W. Xi, X.B. Tian, Single-crystalline gallium nitride microspindles: synthesis, characterization, and thermal stability, Adv. Funct. Mater. 14 (2004) 464-470.

[22] Y. Xie, Y.T. Qian, W.Z. Wang, S.Y. Zhang, Y.H. Zhang, A Benzene-Thermal Synthetic Route to Nanocrystalline GaN, Science, 272 (1996) 1926-1927.

[23] K.Y. Bao, L. Shi, X.D. Liu, C.Z. Chen, W.T. Mao, L.L. Zhu, J. Cao, Synthesis of GaN Nanorods by a Solid-State Reaction. J. Nanomater. 2010. 